Bhattacharya S, Messenger S, editors. The global eradication of smallpox. Hyderabad: Orient Blackswan; 2010. 206 p.

Érico Silva Muniz

Programa de Pós-Graduação em História das Ciências e da Saúde, Casa de Oswaldo Cruz, Fundação Oswaldo Cruz.

\section{Memórias da erradicação da varíola}

Em meio às comemorações dos trinta anos de erradicação mundial da varíola no ano de 2010 , novas e outras luzes foram lançadas sobre esta conquista da Saúde Pública, principalmente sobre o processo histórico e social que a viabilizou. O sucesso da campanha organizada pela Organização Mundial da Saúde (OMS) em parceria com governos nacionais e agências de cooperação e os sentidos a ela atribuídos podem agora ser mais bem avaliados com o livro The global eradication of smallpox, que traz depoimentos sobre os esforços realizados por médicos, sanitaristas e técnicos em diferentes experiências nacionais. $\mathrm{O}$ debate sobre a campanha e o legado deixado para os programas de imunização apresentam-se ao leitor na forma de depoimentos que motivarão historiadores, cientistas sociais, sanitaristas e profissionais da área de saúde em geral a complexificar suas interpretações sobre a Saúde Pública da segunda metade do século XX, numa constante dinâmica de relacionar passado, presente e futuro. $O$ livro apresenta ao leitor as dificuldades, incertezas, lições e inovações presenciadas em campo na Ásia e na África, tratando das resistências e dos sucessos obtidos. Os depoimentos editados por Sanjoy Bhattacharya e Sharon Messenger contribuem ainda para os debates atuais sobre a possibilidade de erradicação de outras doenças, sobre a cooperação internacional e modelos de campanhas de saúde e intervenções biomédicas.

A campanha para erradicação da varíola foi proposta na OMS em 1959, tendo, no entanto, sido reestruturada em 1965 e intensificada em 1967, quando esta agência especializada das Nações Unidas aumentou o financiamento para produção dos imunizantes em laboratórios localizados nos países endêmicos, garantiu maior fiscalização da qualidade dos produtos e introduziu a vacina liofilizada e a agulha bifurcada em larga escala. Estavam consolidadas as bases para erradicar a varíola, doença que contava com longa tradição de planos de imunização, que ocupava espaço importante na agenda da Saúde Pública e que passara àquele momento a contar com sólida dotação orçamentária da cooperação internacional (financiamento de agências e governos nacionais).
Os depoimentos dos líderes dessa campanha indicam as variadas possibilidades de enquadramentos vividos com o passar dos anos. As memórias dos chamados "guerreiros da varíola", com suas subjetividades e ênfases, são apresentadas a partir do local e do momento de que se fala, isto é, trinta anos depois, em tom heroico e emocional e de celebração da capacidade humana em libertar o mundo de um de seus maiores e mais antigos flagelos: a varíola. As ponderações sobre os limites, usos e especificidades do trabalho com fontes orais já foi discutida por autores como Bourdieu ${ }^{1}$, Levi $^{2}$, Loriga ${ }^{3}$ e Le Goff ${ }^{4}$, que indicaram como as narrativas biográficas são permeadas de subjetividades reforçadas a partir de grifos e esquecimentos, contando ainda com uma dimensão coletiva para além da lembrança pessoal da história vivida. O que não se deve perder de vista seguramente é que depoimentos são releituras posteriores de eventos passados, e por isso dizem muito também do tempo presente, são memórias com momento e local determinados. Por sua vez, entrevistas e histórias orais suprem lacunas que, dificilmente, investigações restritas a documentos escritos, acordos, autobiografias, cartas ou periódicos poderiam revelar.

No livro, essas recordações são discutidas na introdução por Sanjoy Bhattacharya, que apresenta os chamados "guerreiros da varíola", designação que, em si mesma, nos remete a imagens presentes na Saúde Pública de missão, luta, heroísmo, batalha; sempre associadas a metáforas bélicas. O organizador atenta para a diversidade de ideias que se enfrentou em curso no programa e suas muitas dimensões, como a realidade de suporte financeiro ineficaz e as divergências científicas sobre causa e método de controle da doença. Bhattacharya destaca ainda elementos comuns entre os depoimentos, como a recorrente lembrança do internacionalismo e a sensação de uma construção coletiva, de um "espírito de colaboração" para a vitória da Saúde Pública.

No primeiro capítulo, Donald A. Henderson, que foi o coordenador do Programa de Erradicação da Varíola na OMS, enfatiza os problemas, dificuldades e equívocos com os quais o programa teve que lidar. O epidemiologista norte-americano fala sobre a criação do programa, suas fases e bastidores, abordando financiamento e momentos de crise da cooperação internacional em saúde. Henderson relatou em sua conferência que a saga para erradicar a varíola foi permeada por "malogros quase insuperáveis, guerras civis, inundações, fome e refugiados" e ressaltou o valor do aprendizado e do grande legado deixado, que seria a possibilida-

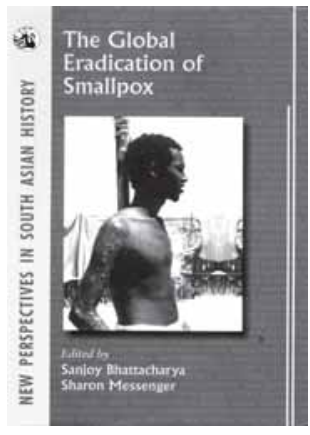


de de imunizar populações contra varíola, difteria, coqueluche, tétano, sarampo e pólio com eficácia, diminuindo a mortalidade infantil em escala global.

No segundo capítulo Joel G. Breman trata da experiência da campanha na África Subsaariana Ocidental e Central. Os serviços realizados nas ex-colonias africanas que haviam recentemente se tornado países independentes foram, segundo o autor, de extrema dificuldade pela precária infraestrutura disponível. Baseado nas lições vividas na Guiné, Breman relata as carências no fornecimento de material de toda natureza, falta de energia elétrica e precária manutenção de equipamentos, o que teria reforçado a necessidade de interação local, numa lógica em que "as boas ideias usadas para erradicar a varíola vieram do campo, e não do escritório central”.

Larry Brilliant e Corrie White Conrad expõem, no terceiro capítulo, suas memórias sobre o longo processo de erradicação da doença na Índia. Responsável pela maior parte dos casos de varíola no mundo desde o final dos anos 1960, a Índia na época já possuía uma população vastíssima, o que tornava a vacinação em massa quase impossível. A principal estratégia adotada foi a de vigilância e contenção de focos da doença. Brilliant e Conrad relatam ainda que a instabilidade política do país e os conflitos territoriais entre Bangladesh e Paquistão afetaram severamente o cotidiano dos serviços. Baseado no sucesso obtido na África, um plano de ação intensificado foi capaz de aumentar a atuação da campanha e a vacinação e de adotar estratégias como a recompensa por notificação de casos, medidas que conduziram à erradicação no país, certificada em 1977.

Ao longo do capítulo quatro, Ciro de Quadros enumera as dificuldades vividas no cotidiano da campanha na região do Chifre da África. Os trabalhos na Etiópia, segundo maior país africano, foram abalados pelas estruturas rudimentares de locomoção e comunicação, realidade que fez com que o país fosse o primeiro a adotar o método de vigilância e contenção em detrimento da vacinação em massa. O relato de Quadros observa ainda o papel das resistências religiosas, as estratégias para superar os problemas da distância entre as aldeias e o empenho do pessoal envolvido na campanha.

O capítulo cinco, de Alan Schnur, traz a perspectiva dos trabalhadores da saúde no campo, tratando de problemas, soluções e da interação entre funcionários nacionais e dirigentes do programa. As atividades piloto testadas por funcionários na solução de problemas por vezes tornavam-se práticas nacionais ou globais, conferindo ao campo uma função de permanente pesquisa e gestão. Entre as práticas introduzidas por funcionários, Schnur cita o cartão de reconhecimento de casos, os vigias de porta de casa, a recompensa por notificação e os livros de contenção, o que atribuiria um "empoderamento" do trabalhador de campo, função importante na dinâmica dos serviços.

No último capítulo Isao Arita e Myuki Nakame discutem o sucesso da campanha e as perspectivas para o século XXI. Ao debaterem o conceito de erradicação, os esforços envolvidos nos programas no século atual e o contexto no qual se inscrevia a campanha da varíola (tradição de pesquisa, existência de método considerado eficaz por comunidades científicas e experiências bem-sucedidas), os autores consideram que o sucesso desse programa influenciou os rumos dos serviços de saúde quanto ao otimismo da possibilidade de erradicação de doenças e no destaque da necessidade de fortalecer os serviços básicos de saúde.

Contando ainda com fotografias de populações, de vacinações, de médicos, moradores e encontros de equipes em campo, o livro apresenta a convivência entre humanidade e miséria, condições adversas de transporte (rodoviário e aquaviário) e habitação e sucesso da empreitada. Ademais, o estudo dos esforços dessa campanha global, que é por muitos considerada a maior vitória da cooperação internacional em saúde, auxilia a interpretar este singular evento ao mesmo tempo celebrado e controverso. O grande ausente deste livro é o Brasil, último país a erradicar a varíola na região das Américas e onde importantes experiências de vacinação em massa foram realizadas com o uso do injetor ${ }^{5}$. Não é função dessa história fornecer um receituário ou ensinar lições para profissionais e programas de saúde; cabe, porém, problematizar e contextualizar conceitos e práticas em voga em determinado momento, com suas rupturas e continuidades, considerando-se erros e acertos. Em suma, The global eradication of smallpox, além de revelar dimensões não apreendidas por fontes oficiais, é extremamente informativo e surge como importante referência para os estudos no campo da história e da Saúde Pública. 


\section{Referências}

1. Bourdieu P. A ilusão biográfica. In: Ferreira MM, Amado J, organizadores. Usos \& abusos da história oral. Rio de Janeiro: Fundação Getúlio Vargas; 1996.

2. Levi G. Os usos da biografia. In: Ferreira MM, Amado J, organizadores. Usos \& abusos da história oral. Rio de Janeiro: Fundação Getúlio Vargas; 1996.

3. Loriga S. A biografia como problema. In: Revel J, organizador. Jogos de escalas: a experiência da microanálise. Rio de Janeiro: Fundação Getúlio Vargas; 1998.

4. Le Goff J. São Luís: biografia. Rio de Janeiro: Record; 1999.

5. Hochman G. Priority, invisibility and eradication: the history of smallpox and the Brazilian Public Health agenda. Medical History 2009; 53:229-252. 